\title{
GCU
}

Glasgow Caledonian

University

University for the Common Good

\section{AR guidance system for traffic circumvention and collision avoidance: emergency services case study}

Bram-Larbi, K.F.; Charissis, V.; Khan, S.; Lagoo, R.; Drikakis, D.; Harrison, D.K.

Published in:

2021 IEEE International Conference on Consumer Electronics (ICCE)

DOI:

10.1109/ICCE50685.2021.9427708

Publication date:

2021

Document Version

Author accepted manuscript

Link to publication in ResearchOnline

Citation for published version (Harvard):

Bram-Larbi, KF, Charissis, V, Khan, S, Lagoo, R, Drikakis, D \& Harrison, DK 2021, AR guidance system for traffic circumvention and collision avoidance: emergency services case study. in 2021 IEEE International Conference on Consumer Electronics (ICCE)., 9427708, Proceedings of ... IEEE International Symposium on Consumer Electronics, IEEE, 39th IEEE International Conference on Consumer Electronics, 10/01/21. https://doi.org/10.1109/ICCE50685.2021.9427708

\section{General rights}

Copyright and moral rights for the publications made accessible in the public portal are retained by the authors and/or other copyright owners and it is a condition of accessing publications that users recognise and abide by the legal requirements associated with these rights.

Take down policy

If you believe that this document breaches copyright please view our takedown policy at https://edshare.gcu.ac.uk/id/eprint/5179 for details of how to contact us. 


\section{GCU}

Glasgow Caledonian

University

University for the Common Good

\section{AR Guidance System for Traffic Circumvention and Collision Avoidance: Emergency Services Case Study}

Bram-Larbi, Kweku; Charissis, Vassilis; Khan, Mohammed Soheeb; Lagoo, Ramesh;

Drikakis, Dimitris; Harrison, David

Publication date:

2020

Document Version

Peer reviewed version

Link to publication in ResearchOnline

Citation for published version (Harvard):

Bram-Larbi, K, Charissis, V, Khan, MS, Lagoo, R, Drikakis, D \& Harrison, D 2020, 'AR Guidance System for Traffic Circumvention and Collision Avoidance: Emergency Services Case Study', Paper presented at IEEE International Conference on Consumer Electronics, Las Vegas, United States, 10/01/21 - 12/01/21.

\section{General rights}

Copyright and moral rights for the publications made accessible in the public portal are retained by the authors and/or other copyright owners and it is a condition of accessing publications that users recognise and abide by the legal requirements associated with these rights.

Take down policy

If you believe that this document breaches copyright please view our takedown policy at https://edshare.gcu.ac.uk/id/eprint/5179 for details

of how to contact us. 


\title{
AR Guidance System for Traffic Circumvention and Collision Avoidance: Emergency Services Case Study
}

\author{
K.F. BRAM-LARBI ${ }^{1}$, V. CHARISSIS ${ }^{1}$, S. KHAN ${ }^{1}$, R. LAGOO $^{1}$, D. DRIKAKIS ${ }^{2}$ and D. K. HARRISON ${ }^{3}$ \\ ${ }^{1}$ Glasgow Caledonian University, Glasgow, UK \\ School of Computing, Engineering and Built Environment \\ Virtual Reality Driving Simulation Laboratory \\ ${ }^{2}$ University of Nicosia, Nicosia, Cyprus \\ School of Sciences and Engineering \\ ${ }^{3}$ Glasgow Caledonian University, Glasgow, UK \\ School of Computing, Engineering and Built Environment \\ Department of Mechanical Engineering
}

\begin{abstract}
Circumventing motorway traffic can be a challenging task for the Emergency Services' vehicles. This work presents a preliminary Human-Computer Interface (HCI) design which employs Augmented Reality (AR) and Artificial Intelligence (AI) to provide in real-time the best manoeuvring and speed options to the ES driver, through a full-windscreen Head-Up Display (HUD). The system design was presented to 30 ES drivers from Africa and Europe. Their subjective feedback and expectations of the proposed feedback were analysed and offered an insight into the similarities and differences of requirements for the two groups that perform the same activities in different environments.
\end{abstract}

Keywords- Augmented Reality, Artificial Intelligence, Emergency Services, Head-Up Display, Collision Avoidance, Driver Distraction, Smart Cities

\section{INTRODUCTION}

The provision of care, safety and support to citizens of a country in dire situations requires rapid and efficient deployment of Emergency services personnel. For example, an ambulance that can provide advanced care to a patient before he or she gets to a hospital is a crucial link to a chain of survival in major cases (i.e. cardiac arrest, gunshot wounds, stroke, car-accident) as well as any ailment that might befall a person $[1,2]$. This view on the importance of Emergency Response Services, especially ambulances is shared by the World Health

Organisation (WHO) which recognized that improved organization and planning for provision of trauma and emergency care is an essential part of integrated health-care delivery. Furthermore, this plays an important role in preparedness for, and in response to, mass-casualty incidents, and can lower mortality, reduce disability and prevent other adverse health outcomes arising from the burden of everyday injuries. To this end, WHO suggested that additional efforts should be made globally to strengthen the provision of trauma and emergency care to ensure timely and effective delivery to those who need it, in the context of the overall health-care system, and related health and health-promotion initiatives [3]. The call by the WHO to strengthen the provision of trauma and emergency care is indicative in itself of the major challenges facing the provision of emergency response services. In multiple occasions, the expected duration of an ES journey extends from few minutes to hours losing crucial time for attending to victims of major incidents [4]. In other parts of the world, inadequate road infrastructure affected further the provision of support to the local population [5].

Although the various traffic, weather and road conditions might vary in different countries, one common issue is the navigation through variable traffic densities, which forces the ES drivers to fluctuate heavily their speed and perform abrupt manoeuvring to circumvent any traffic bottlenecks occurred. This paper presents a prototype system that supports the decision-making process of the driver with the use of emerging technologies such as AR and AI. In turn, the paper evaluates the feedback derived from a qualitative study with 30 ES drivers/staff from both Africa and Europe. The two equally divided cohorts are then compared to identify commonalities and differences in their requirements for reaching in a timely and safe manner on their destination. Concluding, the paper will present a tentative plan of future work aiming to optimize the proposed system and provide additional support to the ES personnel. 


\section{CURREnT Issues}

\section{A. Traffic, Weather and Road Conditions}

ES drivers face a great risk of collision not only from on-coming traffic since they are sometimes required to drive in the opposite lane when there is stagnant traffic, but also collision into inattentive vehicles and pedestrians, especially in unfavourable weather conditions. The latter could be a major hindrance to the fast and effective response times of ES vehicles to emergency scenes.

Adverse weather conditions (i.e. fog, heavy rain, snowstorm, sandstorm, sun-glare) serve as major visual impairments since they limit significantly the driver's visibility, thus increasing the risks of potential collisions [6-8]. These issues can be particularly intense on the ES vehicles which need to perform abrupt manoeuvres whilst maintaining relatively high speeds. The traffic issue could also be prominent in areas where the road network is inadequately developed or neglected. In such case, the sheer volume of vehicles or the effort of drivers to avoid potential obstacles (i.e. potholes, uneven tarmac or road-works) create further bottlenecks and increase the collision probabilities. Passenger vehicles could also affect significantly the traffic flow especially in multilane highways, by creating sequential bottlenecks and traffic waves due to lead driver's distraction [9].

\section{B. Driver Distraction}

The infotainment systems could be held responsible for the majority of collisions occurred in passenger vehicles as they magnify the aforementioned issues by reducing driver's attendance on the road [10]. This issue can also affect the ES vehicle drivers which are tuned-in to numerous information systems presenting in real-time destination data, patient/victim information, navigation data, and different ES groups' coordination information for approaching to the same Point Of Interest (POI) amongst other. Their attention might be further hindered by the activities on the rear passengers which can increase the collision probability [11].
Notably, this flooding of information from different activities could overwhelm a driver and result in a potential collision, jeopardising the safety of the ES vehicle occupants as well as the occupants of the neighbouring vehicles [12].

\section{Driver Manouvering Patterns}

Due to the necessity of ES vehicles' prompt arrival to the POI, drivers are trained to perform complex manoeuvres whilst moving in high speeds through various traffic densities [13]. Yet the aforementioned different conditions and cognitive load from the on-board information devices could affect their decision making capability and reduce their response times.

In addition, the ES drivers are trying to follow the navigation information and respond to other in-vehicle requirements. This further affects their concentration. The higher than usual speeds of the ES vehicles are also reducing drastically the remaining Time To Collision (TTC) to the lead or surrounding vehicles as presented in Figure 1 [6]. As such the driver has even less time to respond to any abrupt changes in the traffic flow.

\section{CURRENT SOlutions}

A plethora of current and emerging technologies such as Radio Data System (RDS), Self-Organising Traffic Information System (SOTIS), and Vehicular Ad-Hoc Networks (VANETS) have been utilised, aiming to support the ES driver's decision-making process and offer an early warning to the neighbouring passenger vehicles regarding the immediacy of the ES vehicle [14].

RDS is a communication protocol standard for embedding small amounts of digital information in conventional FM radio broadcasts, which is used widely by Emergency Response Personnel. Building onto this, previous studies utilised further this system to extend the signal and warn neighbouring vehicles with regards to the direction, speed and proximity of the incoming ES vehicle [14,15].

VANETS are also incorporated in various research and commercial application aiming to propagate information between vehicles (V2V) and infrastructure (V2I) [16, 17]. The

\section{Option 2}

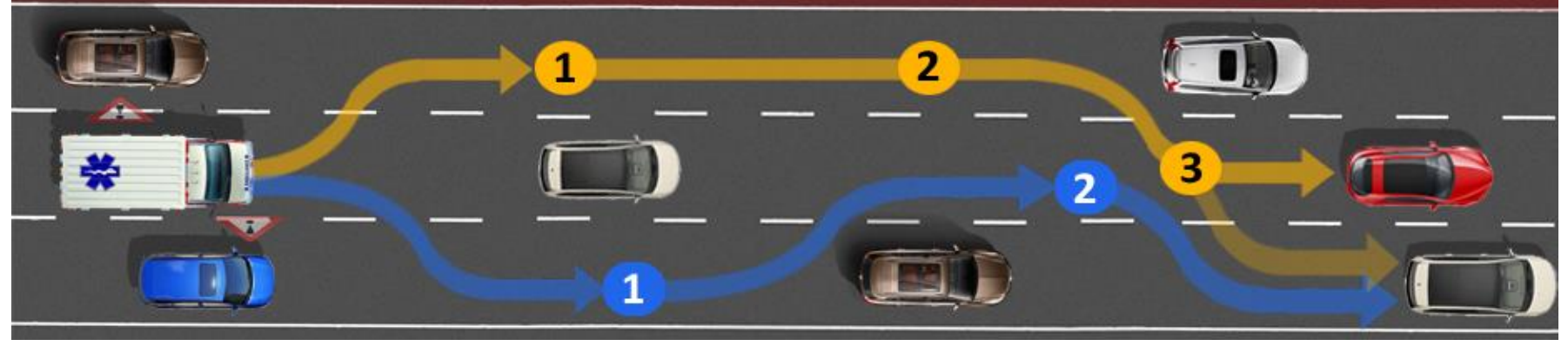

Fig. 1. Manouvering options and steps for successfully circumventing the traffic in emergency case scenarios 
transmission of positioning and speed data could service the calculation of the different manoeuvring steps and the required speed for the ES vehicle to safely pass through the traffic.

Additional attempts to resolve the driver's decision-making process resulted in current navigation devices which provide detailed information about the different routes available, traffic congestion, type of road (i.e. motorway, rural, urban network) and Estimated Time of Arrival (ETS) among other information. Yet, all the above systems fail to offer a step by step real-time guidance to the driver and alleviate the pressure and cognitive load of combining the above information to manoeuvre successfully through the traffic as illustrated in Figure 1.

\section{PROPOSED AR/AI SOLUTION}

Based on the above observations the interface design for the proposed AR system follows the same simplified visual input of crucial information following previous work and experimentation with AR HUD systems [6, 17]. The selection of full-windshield AR HUD provides larger estate for the superimposition of information in scale 1:1 to the external environments. This mitigates any delay issues that drivers might encounter by trying to visualise small-size HUD information in real-scale and reduces the probability of collision [18-22].

The minimalistic symbolic representation of the proposed manoeuvring options and required speeds are presented directly on the real-life road through the full-windshield AR HUD system as presented in the VR Driving Simulator in Figure 2 [6, 23]. The direction of the manoeuvres is presented by colour-coded arrows; red, amber, green and blue, which represent the different risk-level of the manoeuvring option (i.e. red is the riskier and blue is the easiest to perform).

Based on our previous consultation with both ES and civilian drivers, it was deemed ideal to divide the proposed manoeuvering routes into different stages depicted by a colour coded circle. Each circle is the safe point reached on each lane change $[9,13]$.

Additionally, this provides further time for the system to recalculate the trajectory of the next manoeuvre and reduce any potential safety issues that might have arisen by the traffic flow changes. The latter process is tasked to the AI part of the system

which will provide the proposed options through auditory ques aiming to complement the visual representation of the AR part. The AI system under development will resume the role of

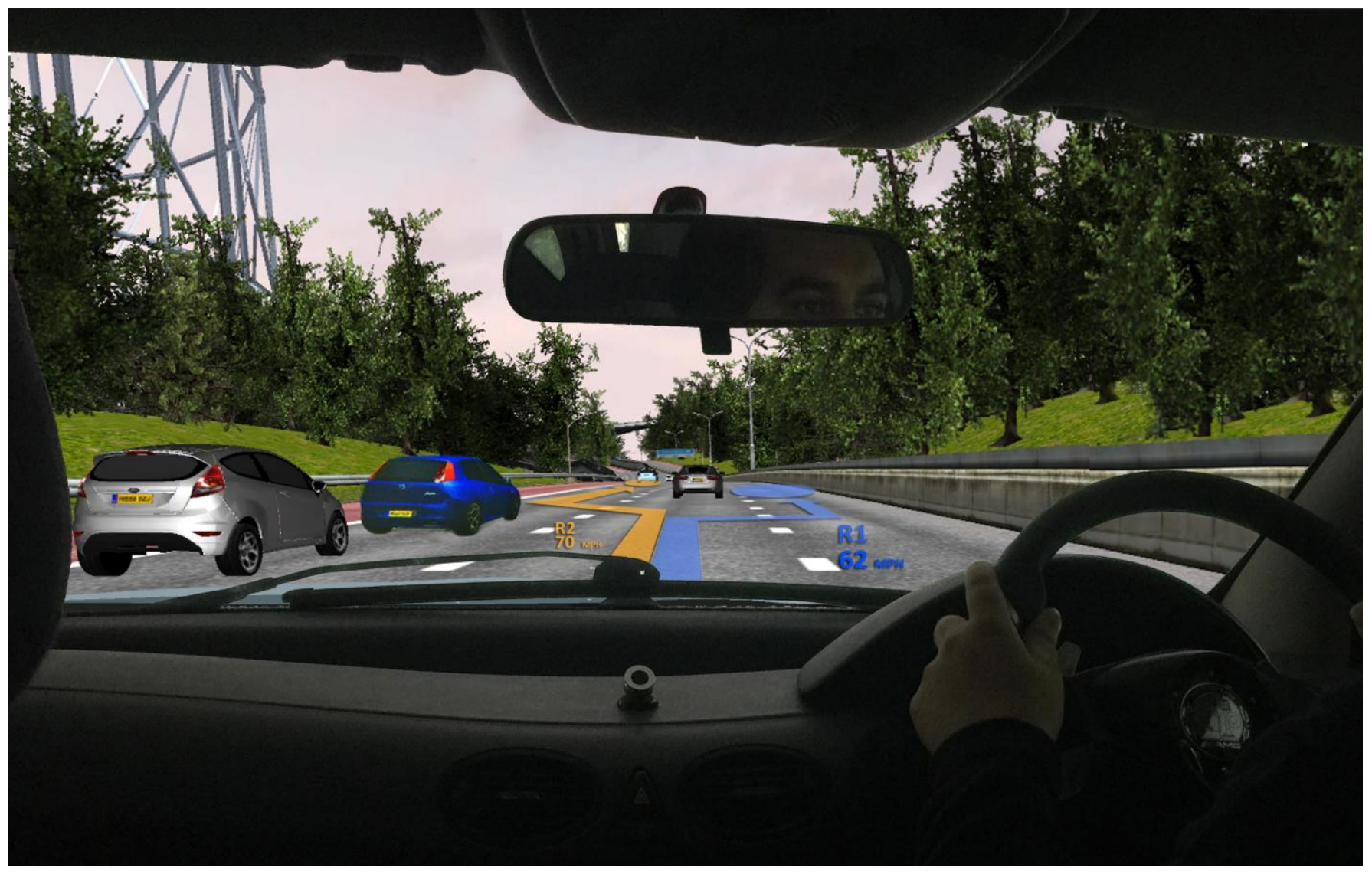

Fig. 2. Manouvering options and steps for successfully circumventing the traffic in emergency case scenarios. 
a digital co-driver suggesting calmly and in advance, any potential moves that could decrease the ETA, whilst maintaining the safety of the driver and the neighbouring vehicles.

The AI system will be further trained through previous accident data provided by the local police department. Also, the VR simulations performed by different volunteer drivers in the VR Driving Simulator will provide multiple options for collision avoidance manoeuvres and their suitability based on traffic, weather and accident scenarios [24-26].

\section{SySTEM EVALUATION}

\section{A. Survey Rationale and Structure}

The evaluation process started with a pre-test questionnaire. This first questionnaire acquired the drivers' demographic information, personal driving experiences, daily issues encountered and their expectations from a potential system that would aim to offer some solutions.

The second stage was the presentation of the current in-vehicle navigation and infotainment systems and the related driver distraction issues that increase the probability of collision. In turn, a presentation of a demo version of the proposed AR/AI HUD (as presented in Figure 2) has been contrasted to existing navigation methods in a typical rear-collision scenario described below [6, 27].

The third stage of the evaluation was designed to acquire the ES drivers' subjective feedback and identify the potential usability benefits and issues of the proposed HCI design. The results of this evaluation could further clarify the acceptability of a full-windshield AR HUD interface complimented by an AI Co-driver. Their responses and subjective feedback could further improve the system design prior to the final version evaluation in the Virtual Reality Driving Simulator (VRDS) Laboratory. This paper will focus on the main 18 questions of the post questionnaire presented in Table 1 [13].

\section{B. Participants}

The investigation was performed with the use of 30 participants, which were all ES staff. The participants' age was spanning from 18 to 55 years old. The 30 drivers were formed by two groups of 15 drivers each, from Africa (Ghana) and Europe (UK and Greece) respectively. The groups were analysed individually and as a whole aiming to identify differences and commonalities on their requirements and expectations of a system such as the proposed one.

\section{Driving and Collision Scenario}

A rear collision scenario with the lead-vehicle has been presented to the participants. The accident scenario employed for this survey follows the exact pattern with previous accident scenarios used for the evaluation of former Advanced Driver
Assistance Systems (ADAS) which evaluated HUD prototypes against typical Head Down Displays (HDD) [6, 10, 28].

This was deemed essential for preserving the uniformity with previous and future experiments that involve HUD and AR applications versus traditional in-vehicle infotainment systems.

Table 1: Post-questionnaire for the ES staff.

\section{Post-Questionnaire}

Q11. Did you find the interface design simple and clear? $\square 1 \quad \square 2 \quad \square 3 \quad \square 4 \quad \square 5 \quad$ (1 Very Simple - 5 Very Difficult)

Q12. Do you think that interface design and colour coding would be useful to convey the manoeuvring information?

$\square 1 \quad \square 2 \quad \square 3 \quad \square 4 \quad \square 5 \quad$ (1 Very Useful - 5 Not Useful at all)

Q13. Would you be interested to have $\boldsymbol{A R}$ navigation/guidance system in the ES vehicle?

$\square 1 \quad \square 2 \quad \square 3 \quad \square 4 \quad \square 5 \quad$ (1 Very Interested - 5 Not Interested at all)

Q14. Would you be interested to have $\boldsymbol{A I}$ navigation/guidance system in the ES vehicle?

$\square 1 \quad \square 2 \quad \square 3 \quad \square 4 \quad \square 5 \quad$ (1 Very Interested - 5 Not Interested at all)

Q15. Would you be interested to have $\boldsymbol{A R}$ navigation/guidance system in the civilian vehicles?

$\square 1 \quad \square 2 \quad \square 3 \quad \square 4 \quad \square 5 \quad$ (1 Very Interested - 5 Not Interested at all)

Q16. Would you be interested to have $\boldsymbol{A I}$ navigation/guidance system in the civilian vehicles?

$\square 1 \quad \square 2 \quad \square 3 \quad \square 4 \quad \square 5 \quad$ (1 Very Interested - 5 Not Interested at all)

Q17. Would you be interested to have real-time guidance suggestions by an AI/AR system?

$\square 1 \quad \square 2 \quad \square 3 \quad \square 4 \quad \square 5 \quad$ (1 Very Interested -5 Not Interested at all) Q18. Do you think that the AR/AI proposed system could replace other guidance systems?

$\square$ Yes $\square$ No

Q19. Do you think it would be a helpful system (AI/AR) to integrate into future ES vehicles?

$\square$ Yes $\quad \square$ No

Q20. Do you think it would be a helpful system (AI/AR) to integrate into future civilian vehicles?

$\square$ Yes $\square$ No

Q21. Do you have any other suggestions, comments or thoughts regarding the proposed AR/AI system? If yes please use the space below to write your comments.

$\square$ Yes $\quad \square$ No

\section{RESULTS AND DISCUSSION}

The questions 11-20 have provided an indicative appraisal of the proposed system's acceptance by the users and their future expectations. The presentation of data in Figure 4, shows the responses of the overall cohort of the 30 drivers, whilst Figure 5 presents the feedback provided by each of the groups. The drivers' responded positively towards the interface design (Question 11) with regards to the simplicity and clarity of information provided. Question 12 which explored the colour coding of the AR symbolic representations also received positive responses from $93 \%$ of the participants. The acceptability of an AR navigation/guidance system in the ES vehicles, explored in Question 13, received a 90\% acceptance rate. Question 14, although it received overall positive responses, presented also a variety of neutral and negative responses revealing some anxiety of the users regarding the extent of the AI involvement on the driving process. These responses were posed exclusively from the European drivers as 
can be seen in Figure 5. The trustworthiness of such systems has been affected by early generations of vehicular navigation systems which occasionally provided anecdotal guidance information for traffic avoidance or alternative faster routes.

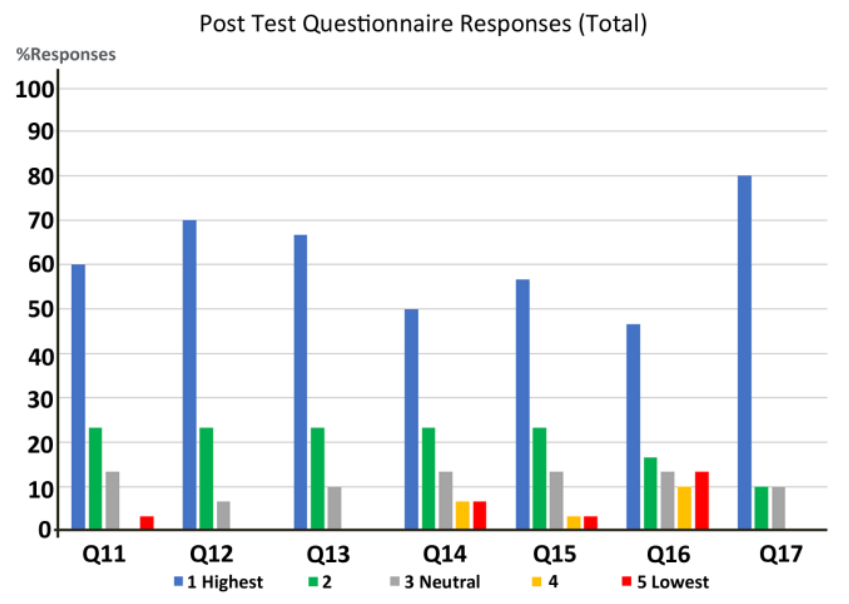

Fig. 4. Post Questionnaire Results for all the 30 drivers (Questions 11-17)

Nevertheless, this could be alleviated with the introduction of new generations of drivers that are accustomed to the AI support throughout their daily activities. Similarly, Question 16 raised even more concerns for the use of AI Co-Driver for civilian vehicles, although some vehicles have already a Technology Readiness Level (TRL) 4 and some are pursuing level 5 for fully autonomous driving without geofencing limitations. Notably, the proposed system is not taking the control fully or partially from the driver, but only supervises, predicts and suggests the best possible manoeuvres and speeds, to achieve faster and safer traffic circumvention. Yet even this artificial intervention was considered a potential issue by some of the users which were concerning both the African and the European groups as illustrated in Figure 5.

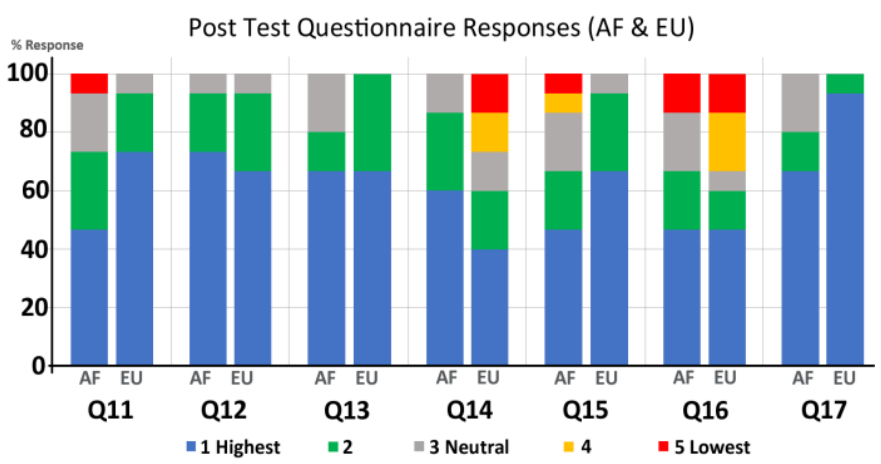

Fig. 5. Comparison of Post Questionnaire Results between AF and EU drivers

Question 15 presented a positive overview of $80 \%$, with some users expressing minor concerns $(6 \%)$ for the superimposed AR guidance interface. The concerns regarding the AI were counterbalanced in Question 17 in which $90 \%$ of the users were keen to receive time-sensitive guidance information by the proposed AR/AI system. Questions 18, 19 and 20 have almost unanimously received positive responses with $90 \%, 100 \%$ and $87 \%$ respectively. The negative responses formed a small segment of the overall feedback and echoed the concerns expressed in the previous questions primarily related to the $\mathrm{AI}$ involvement in the driving process. The latter three questions were in par with the previous evaluations $[9,14]$. Interestingly both professional (ES) and passenger vehicle drivers are both keen to see this technology in their future vehicles.

\section{CONCLUSIONS}

This paper explored the design rationale of a prototype AR/AI system that could present real-time suggestions for collision avoidance and high-speed manoeuvring. The system is custom-designed for ES vehicles and their requirements for fast yet safe circumvention of traffic when is essential. The provision of information is provided by a multimodal interface which superimposes guidance information directly to the real-life environment with the use of a full windshield HUD device whilst an AI Co-driver suggests vocally the presented visual AR options.

In turn, the paper presented a preliminary evaluation of the AR/AI prototype system by $30 \mathrm{ES}$ drivers forming two arms of 15 drivers each, representing two different continents namely Africa and Europe. Despite some differences in daily driving requirements, their overall feedback highlighted very similar preferences and concerns with some elements of the emerging technologies discussed analytically in the results' section.

The evaluation provided encouraging results for the acceptance of the proposed emerging technologies (i.e. AR, AI). The collaboration of human-machine to achieve improved spatial and situational awareness was perceived as a positive future outcome by the ES staff. Yet, the users expressed some concerns regarding the employment of AI for the provision of real-time calculated manoeuvring and collision avoidance options. The future plans for the development of this work are to deploy the system on our scale 1:1 VR Driving Simulator and expand the evaluation process both in users'numbers and in the level of accident scenarios' complexity.

\section{REFERENCES}

[1] R.O. Cummins, J.P. Ornato, W.H. Thies and P.E. Pepe, "Improving survival from sudden cardiac arrest: the chain of survival concept", A statement for health professionals from the Advanced Cardiac Life Support Subcommittee and the Emergency Cardiac Care Committee, American Heart Association. Circulation; 83:1832 - 1847, 1991.

[2] H. Hsiao, J. Chang and P. Simeonov, "Preventing Emergency Vehicle Crashes: Status and Challenges of Human Factors Issues", Sage, Vol. 60 no. 7, pp. 1048-1072 https://doi.org/10.1177/0018720818786132, (2018).

[3] C. Mock, C. Juillard, M. Joshipura, and J. Goosen "Strengthening care for the injured: success stories and lessons learned from around the world", World Health Organisation, pp1-95, ISBN 978924156396 3, 2010. 
[4] N. Smith, "A National Perspective on Ambulance Crashes and Safety: Guidance from the National Highway Traffic Safety Administration on ambulance safety for patients and providers", NHTSA Report, EMS World, pp. 91-94, 2015.

[5] M. Osei-Ampofo, G. Oduro, R. Oteng, A. Zakariah, G. Jacquet, and P. Donkor, "The Evolution and Current State of Emergency Care in Ghana". African Journal of Emergency Medicine, Elsevier, vol 2, no 3, pp 52 - 58, 2013.

[6] V. Charissis, and S. Papanastasiou, "Human-Machine Collaboration Through Vehicle Head-Up Display Interface", in International Journal of Cognition, Technology and Work, P. C. Cacciabue and E. Hollangel (eds.) Springer London Ltd Volume 12, Number 1, pp 41-50, DOI: 10.1007/s10111-008-0117, 2010.

[7] N. Chakrabarty and K. Guptab, "Analysis of Driver Behaviour and Crash Characteristics during Adverse Weather Conditions", 2nd Conference of Transportation Research Group of India, (CTRG) Procedia - Social and Behavioral Sciences, Elsevier, 104, pp 1048 - 1057, 2013.

[8] K. F. Bram-Larbi, V. Charissis, S. Khan, R. Lagoo, D. K. Harrison and D. Drikakis, "Collision Avoidance Head-Up Display: Design Considerations for Emergency Services' Vehicles," 2020 IEEE International Conference on Consumer Electronics (ICCE), Las Vegas, NV, USA, pp. 1-7, doi: 10.1109/ICCE46568.2020.9043068, 2020.

[9] C.F. Daganzo, "A Behavioural Theory of Multi-Lane Traffic Flow. Part 1 Long Homogenous Freeway Sections", Research Report UCB-ITS-RR-99-5, Institute of Transportation Studies, University of California, Berkley, 1999.

[10] R. Lagoo, V. Charissis and D. Harrison, "Mitigating Driver's Distraction with the use of Augmented Reality Head-Up Display and Gesture Recognition System", in IEEE Consumer Electronics Magazine (CEM) Journal, Vol. 8, Issue: 5, pp.79-85, DOI: 10.1109/MCE.2019.2923896, 2019.

[11] S.Wang, V.Charissis, and D.Harrison, "Augmented Reality Prototype HUD for Passenger Infotainment in a Vehicular Environment", in Advances in Science, Technology and Engineering Systems Journal, Vol. 2, No. 3, 634-641, 2017.

[12] G. Saunders and A. Gough, "Emergency Ambulances on the Public Highway Linked with Inconvenience and Potential Danger to Road Users”, Emergency Medical Journal, Vol 20, pp 277-280, 2003.

[13] K.F. Bram-Larbi, V. Charissis, S. Khan, D.K. Harrison and D. Drikakis, "Improving Emergency Vehicles' Response Times with the Use of Augmented Reality and Artificial Intelligence", In Lecture Notes in Computer Science, 2020.

[14] J. D. Moore, S. Boslem, and V. Charissis, "Optimisation of Sound Localisation for Emergency Vehicle Sirens through Prototype Audio System", Book title: Design, User Experience, and Usability. Theory, Methods, Tools and Practice, Lecture Notes in Computer Science, J. A., Jacko (Ed), Vol. 6770, ISBN 978-3-642-21707-4, pp 177-186, Springer Berlin / Heidelberg, 2011.

[15] S. Boslem, J. D. Moore and V. Charissis, “Investigating the Improvement of the Localisation Propensity and Impact of the Emergency Vehicle Sirens", in Proceedings of the Society of Automotive Engineers (SAE) World Congress 2011, 12-14 April, Detroit, Michigan, USA, 2011.

[16] Y. Moroi and K. Takami, "A method of securing priority-use routes for emergency vehicles using inter-vehicle and vehicle-road communication", IEEE 7th International Conference on New Technologies, Mobility and Security (NTMS), 2015.

[17] V. Charissis, S. Papanastasiou, W. Chan, and E. Peytchev, "Evolution of a full-windshield HUD designed for current VANET communication standards", IEEE Intelligent Transportation Systems International Conference (IEEE ITS), The Hague, Netherlands, pp. 1637-1643, DOI: 10.1109/ITSC.2013.6728464, 2013.

[18] H. Okumura, T. Sasaki, A. Hotta and M. Sekine, "Wide Field-of-View and high visibility 3D CG technologies for AR HUDs," 2020 IEEE International Conference on Consumer Electronics (ICCE), Las Vegas, NV, USA, pp. 1-5, doi: 10.1109/ICCE46568.2020.9043126, 2020.
[19] J. L. Gabbard, M. G. Fitch, K. Hyungil, "Behind the Glass: Driver Challenges and Opportunities for AR Automotive Applications", Proceedings of the IEEE, Vol. 102:2, pp.124-136, DOI: 10.1109/JPROC.2013.2294642, 2014.

[20] V. Charissis and M. Naef, "Evaluation of Prototype Automotive Head-Up Display Interface: Testing Driver's Focusing Ability through a VR Simulation," 2007 IEEE Intelligent Vehicles Symposium, Istanbul, 2007, pp. 560-565, doi: 10.1109/IVS.2007.4290174, 2007.

[21] H. Okumura, A. Hotta, T. Sasaki, K. Horiuchi, N. Okada, "Wide field of view optical combiner for augmented reality head-up displays, 2018 IEEE International Conference on Consumer Electronics (IEEE ICCE), DOI: 10.1109/ICCE.2018.8326064, 2018.

[22] H.S. Park, M.W. Park, K.H. Won, K.H. Kim, and S.K. Jung, "InVehicle AR-HUD System to Provide Driving-Safety Information," ETRI Journal, Vol.35, No.6, pp.1038-1047, 2013.

[23] R. Lagoo, V. Charissis, W. Chan, S. Khan and D. Harrison, "Prototype gesture recognition interface for vehicular Head-Up Display system", IEEE International Conference on Consumer Electronics (IEEE ICCE), Las Vegas, USA, pp.1-6, Jan. 2018.

[24] D. Vazquez, L.A., Meyer, J. Marın, D. Ponsa, and D. Geronimo, "Virtual and Real World Adaptation for Pedestrian Detection", IEEE Trans. Pattern Anal. Mach. Intell. 36, 797-809, 2014.

[25] M. Frank, D. Drikakis, V. Charissis, "Machine Learning Methods for Computational Science and Engineering", Computation Journal, Computational Engineering Section, MDPI, 8(1), 15; https://doi.org/10.3390/computation8010015, ISSN 2079-3197, pp 1-36, 2020.

[26] V. Charissis and S. Papanastasiou, "Artificial Intelligence Rationale for Autonomous Vehicle Agents Behaviour in Driving Simulation Environment, Adv. Robot. Autom. Control, pp 314-332, 2008.

[27] G. Weinberg, B. Harsham, and Z. Medenica, "Evaluating the usability of a head-up display for selection from choice lists in cars", 3rd International Conference on Automotive User Interfaces and Interactive Vehicular Applications, Automotive UI '11, pp. 39-46, ACM, 2011.

[28] V. Charissis, S. Papanastasiou, and G. Vlachos, "Comparative Study of Prototype Automotive HUD vs. HDD: Collision Avoidance Simulation and Results," SAE Technical Paper 2008-01-0203, 2008, https://doi.org/10.4271/2008-01-0203.

[29] Y. Liao, G. Li, S. Eben, B. Cheng, and P Green, "Understanding Driver Response Patterns to Mental Workload Increase in Typical Driving Scenarios", in IEEE Access, vol 6, pp. 35890-35900, DOI: 10.1109/ACCESS. 10.1109/ACCESS.2018.2851309, 2018.

[30] M. L. L. Ianninia and R. Dickmanb, "Kinetic Theory of Vehicular Traffic", American Journal of Physics, Vol. 84, no. 135, https://doi.org/10.1119/1.4935895, 2016. 